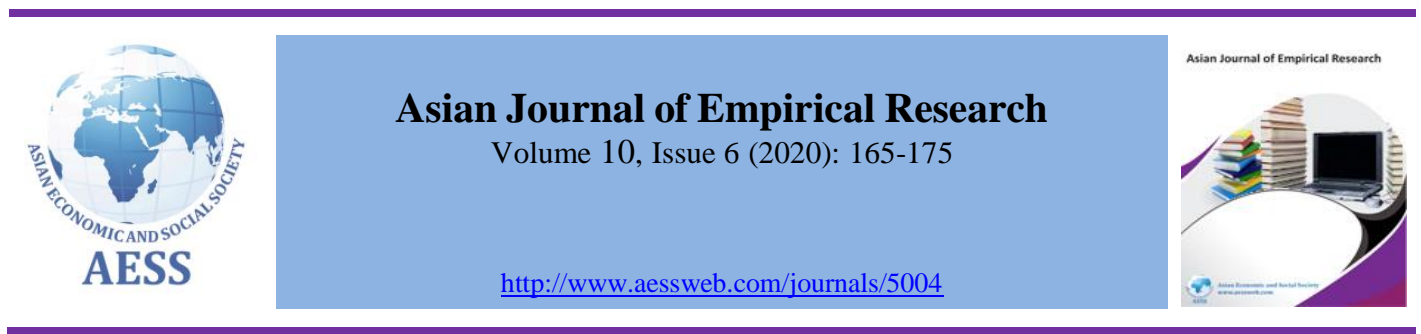

\title{
NEXUS BETWEEN CORONAVIRUS EPIDEMIC AND EDUCATIONAL INDUSTRY: SCENARIO OF ONLINE TEACHING STRATEGIES
}

Chi Hong Leung Department of Management and Marketing, The Hong Kong Polytechnic University, Hong Kong, The People's Republic of China

$\underline{\text { msleung@polyu.edu.hk }}$

\section{ARTICLE HISTORY:}

Received: 23-Mar-2020

Accepted: 04-Jun-2020

Online available: 29 -Jun-2020

\section{Keywords:}

Online teaching and learning,

Class suspension,

Coronavirus epidemic

A BST RA C T
During the global suspension of face-to-face classes due to the
coronavirus epidemic, conducting online teaching becomes an
essential part of offering the best learning experience to students for
this difficult period. This paper suggests various online teaching and
learning tactics in the epidemic. A survey was performed to collect
quantitative feedback from 430 university students taking business
subjects with the implementation of the suggested teaching and
learning activities. Moreover, 40 students were interviewed to
collect qualitative feedback on online teaching practices in other
courses that they experienced. The major findings are that students
were concerned about the quality of online learning materials, the
interaction between students and teachers, technical issues (e.g., the
stability of network connection), and accessibility of online
platforms, learning materials, and their user-friendliness. In
addition, it is found that i) students should be able to access
communicative support and delivered content remotely, ii) teachers
should be supported in adaptation to online teaching, and iii)
technological resources should be utilized to sustain online and
remote teaching and learning.

ABSTRACT

coronavirus epidemic, conducting online teaching becomes an essential part of offering the best learning experience to students for this difficult period. This paper suggests various online teaching and learning tactics in the epidemic. A survey was performed to collect quantitative feedback from 430 university students taking business subjects with the implementation of the suggested teaching and learning activities. Moreover, 40 students were interviewed to collect qualitative feedback on online teaching practices in other courses that they experienced. The major findings are that students were concerned about the quality of online learning materials, the interaction between students and teachers, technical issues (e.g., the stability of network connection), and accessibility of online platforms, learning materials, and their user-friendliness. In addition, it is found that i) students should be able to access communicative support and delivered content remotely, ii) teachers should be supported in adaptation to online teaching, and iii) remote teaching and learning.

\section{Contribution/ Originality}

The paper proposed a certain number of online teaching and learning tactics for the coronavirus epidemic. Educational practitioners may follow these suggested teaching strategies to implement in their schools. Students' attitudes to the relevant online teaching and learning activities were collected for understanding and uncovering their thoughts and opinions.

DOI: 10.18488/journal.1007/2020.10.6/1007.6.165.175

ISSN (P): 2306-983X, ISSN (E): 2224-4425

CrossMark

How to cite: Chi Hong Leung (2020). Nexus between coronavirus epidemic and educational industry: Scenario of online teaching strategies. Asian Journal of Empirical Research, 10(6), 165175.

(C) 2020 Asian Economic and Social Society. All rights reserved 


\section{INTRODUCTION}

The coronavirus epidemic has been influencing people's daily life globally with class suspension and school closures in various countries. China was the first country that suspended classes in February 2020 but the spread of the virus was quick and resulted in the educational disruption of the global scale. It is estimated that about 1.7 billion students are missing class in response to the pandemic. There are about 180 countries that implement nationwide school closure and have an impact on about $98.5 \%$ of the global student population (UNESCO, 2020a). China firstly mandated school closures. Following the Chinese New Year in January 2020, about two hundred million students continued their learning online at home after school closures. In February 2020, all schools in Japan closed to prevent the virus spread. In March 2020, schools across Russia were advised to adopt remote learning and quarantine was in all public schools and universities (Wang and Inouem, 2020). Meanwhile, all schools in the United Kingdom closed and Singapore performed online learning and schools took care of children when their parents worked during the daytime. The Italian government also arranged the complete closure of all educational institutions in the country. Over 1.5 billion students were influenced by class suspension by the end of March, (UNESCO, 2020a). In April, most public and private schools in the United States stopped in-person instruction and schools closed for the rest of the academic year and adapted to online learning.

About 1.3 billion learners across countries are influenced by school closures because of coronavirus outbreak (UNESCO, 2020b). To control the spread of the coronavirus epidemic through social interventions, preventive measures like self-isolation and social distancing prompt the global closures of schools over countries. It is believed that school closure can delay outbreak transmission. Previously, during the 1918-1919 influenza pandemic, school closures were associated with the lower mortality rate in the United States. If school closes late relative to an outbreak, it will become not effective (Jackson et al., 2013). In some situations, when schools reopened after closure, the infection rate was increased. During the 2009 H1N1 Flu pandemic, many countries effectively reduced the infection rate through school closures. Educational facilities in the United States will be closed temporarily to disinfect and clean after infected people have been in this kind of environment. In addition, social distancing is implemented to cancel large gatherings like field trips.

School closures lead to high economic and social loss and impact is serious for the education system and various aspects of students and their families (Hsueh et al., 2010). Students are now deprived of opportunities for learning and development. Some children are reliable on discounted or free meals and nutrition is now compromised during school closure. Moving learning from a physical classroom to home at a large scale presents challenges to teachers. They are not sure of their responsibilities and the way to connect with their students to support learning. Adaptation to online learning platforms becomes frustrating and messy. In a family, parents are not prepared for supporting home-based learning of their children, especially when they are with inadequate resources and limited education. Working parents may leave their children at home and this may result in risky behaviours. If parents may miss work to take care of their children, they may lose wages and reduce productivity. When schools close, calendared assessments and examinations that influence admission to new education levels are thrown into disorder (Lau et al., 2011). Disruptions to these assessments lead to stress for learners while postponing or skipping these examinations raises critical concerns about fairness.

Because educational institutions provide support and structure for economies and communities, school closures for months could have indescribable consequences for children and societies. Senior students may miss important study sessions for the examinations of university admissions while junior students may fall behind in the normal learning schedule. School closures affect the learning outcomes of students and students lack opportunities for development and growth. In addition, schools are hubs of human interaction and social activity. Students are deprived of social contact that is important for development and learning. These disadvantages are more severe for underprivileged students who have fewer learning chances beyond school. After schools have been closed, parents 
struggle to assist in the learning of young children at home when they are with limited resources and education. Parents may get difficulties in finding child care when they are working at home or have lost jobs and wages.

Tertiary institutions are also influenced (Sharma, 2020). The closure of universities and colleagues has extensive impacts on their administrators, teachers, and students. For instance, universities in the United States issues refunds to students for tuition. Most international examinations such as International A Levels and International Baccalaureate (IB) are suspended because of the disruption caused by the coronavirus epidemic. Moreover, some countries suspend their national examination for university admission and contingency measures are taken to grade students who apply for universities in the coming academic year. For example, the English and Chinese oral examinations of Hong Kong's Diploma of Secondary Education (DSE) exams were canceled. About 50,000 local students sit DSE exams and they suffer from the coronavirus closures and disruptions at universities because of protests last year.

It is predicted that for the four-year institutions, globally there is an average of $6-8 \%$ decline of students in the coming academic year $2020 / 21$, and $11 \%$ of potential students decide not to plan to enroll in universities (Educationdata, 2020). In the United Kingdom, universities collectively face a loss of US $\$ 3$ billion in the coming academic year due to predicted drops in student enrolment. In Australia, universities shed up to 21,000 full-time jobs in the current year. One major reason for the drop in revenue is the decrement of international students. For example, Australian universities that critically rely on tuition fees paid by students from China expect to lose US $\$ 2$ to $\$ 3$ billion (Witze, 2020). In Africa, there is an increased risk of university dropouts (>40\%) because of the anticipated recession after the epidemic (EY, 2020). In countries like India and Mexico, the epidemic may result in millions of more children into child labor (Hossain, 2020). One relevant issue of the high dropout rate is the lack of infrastructural support for online learning. There is about $54 \%$ of the global population using the Internet. But in the least developed countries, only $20 \%$ of people get connected to the Internet. Deficiency of the network connection is not the difficulty for the poorest nations in the world. In the United States, there are twelve million children at home with no broadband access. In Los Angeles, $50 \%$ of the students in the school district do not have computers and $25 \%$ cannot access the Internet (Reliefweb, 2020).

Responding to school closures, governments and schools have sought to help students to learn at home and online teaching becomes the major teaching mode during this difficult period. With online learning and open educational platforms, teachers can reach students remotely and reduce the educational disruption that rarely happened in modern history. However, both teachers and students struggle in online classes and they fumble through technologies that leave them confused and frustrated. Inevitable distractions and technological obstacles (such as slow and unstable Internet connection) occur when students are learning alone.

The purpose of this paper is to suggest a number of practices of online teaching in response to the coronavirus epidemics. They were implemented in subjects taught by the author of the paper in a university in Hong Kong. To measure the effectiveness of these teaching practices, a survey was conducted to collect feedback from students. In addition, many students were interviewed to collect their attitudes to online teaching and learning practices that they experienced in other subjects. The rest of this paper will present these suggested online teaching practices followed by the discussion of the results of the survey and the interviews.

\section{SUGGESTIONS FOR ONLINE TEACHING PRACTICES IN THE CORONAVIRUS EPIDEMIC}

\subsection{Conducting synchronous online interactive lessons}

Subject lecturers are suggested to run trial classes with students before the actual ones. It is to make sure that all students are ready for the classes. They should be equipped with suitable software and 
hardware to reduce technical hiccups during the actual class time. Good synchronous online lessons should provide a direct channel for interaction between teachers and students during the online teaching period (Adnan et al., 2017). Before the synchronous lesson, instructions on how to prepare for the lesson (e.g. downloading all materials before the lesson), required learning materials (e.g. hyperlinks to the learning materials and documents) and information about the platform to be utilized should be provided to students. In addition, the purpose of the synchronous session and how it relates to the subject's learning outcome, and what students are anticipated to perform during the session should be clearly explained to them (Cheng et al., 2012).

Teachers should remind students of playing active roles in online learning (Martin et al., 2019). There should be some ways of encouraging students to participate such as engaging students in interactive activities and asking questions and not letting a few students dominate. Teachers may split students into groups if needed to manage large classes and utilize the various teaching tools to enhance student participation in classes (Antonova et al., 2018). For instance, teachers may use simple 'yes/no' polls to engage students in the learning experience. Students may communicate with the teachers through public chats and private messages. Teachers may divide a class into two parts. The first part is lecture while the second part may be, for example, group discussion to enhance interactions among students and engage them in the online learning experience.

Dual computer screens or two different instruments (e.g. mobile phones and desktop computers) may be used together so that the teacher may share the screens for teaching and seeing the questions/texts raised by students. It is also necessary for teachers to monitor the quality of the video and audio shared with students. To set up a surveillance laboratory to monitor the progress and quality of each subject is recommended. A technical staff member may be added as a guest user so that the technician may track the progress of the class like student attendance, and provide support if necessary. A contingency plan should be ready to make sure that the learning contents can be delivered in case the synchronous lesson is not working as planned (Guest et al., 2018). For example, before the lesson starts, the pre-recorded voice-over PowerPoint is available to students.

To provide peer support, it is suggested to team up colleagues who are not familiar with online teaching with another. The experienced colleague may accompany the inexperienced one to provide support and advice. The school may designate computer laboratories with IT personnel to deliver training to colleagues so that they can receive the necessary technical support. To gain experience, the colleagues may observe the online teaching performed by others who are experienced in this (Phelan, 2015).

Teachers are suggested to turn on the online system 15 minutes before the class to make sure that everything functions normally and students can access the session and address any technical issues. Teachers should pay attention to the cursor displayed on their screens as received by the students so that they can follow the teachers. A standalone microphone often gives better sound quality to the students, compared with the built-in one on the computer. Furthermore, teachers should be aware of their voices and it should not be too low or too fast. Teachers are recommended to check whether the recording function is running normally during the class (Malaga and Koppel, 2017). When necessary, teachers are reminded to set suitable control in the system such as controlling students' access to PowerPoint slides during the online lecturing and silencing the students. Wired network is highly suggested to run synchronous teaching because the wireless network may not provide the required speed and stability to ensure the service quality of synchronous online teaching (Mohamad et al., 2015).

\subsection{Providing student support}

Sufficient and timely support and guidance should be provided to students in online learning. Online consultation opportunities should be provided to students regularly during the period of online teaching. Students' requests and inquiries should be responded as short as possible (usually within 24 hours). Regular communication with students may be maintained through various channels such 
as emails, synchronous discussion sessions, and asynchronous discussions online (Eichelberger and Leong, 2019).

\subsection{Creating and using voice-over PowerPoint and videotaped lectures}

To supplement synchronous online lessons good quality lecture presentations such as videotaped lectures and voice-over PowerPoint may be developed. These lecture presentations should be accessed by all learners. It is necessary to explain clearly the relevance of the lecture presented to the subject learning outcomes (Saadé et al., 2012). The video presentations should not be too long. The ideal length should be three to five minutes each. These lecture presentations should be appealing and interspersed with other learning activities like questions and quizzes.

\subsection{Uploading teaching materials}

Fundamental teaching materials of high quality should be easily accessible by students to make sure the efficient delivery of online teaching. Teaching materials are uploaded to the course website and can be accessed by all students taking the subject (Voloshinov et al., 2020). Teaching materials (such as readings, lecture notes, and online resources) in different formats may be offered to students to enhance their learning experience. These materials should be presented consistently and logically (i.e. file structure, navigation, and naming should be consistent) (Hess, 2011).

\subsection{Conducting online asynchronous discussions}

Well-designed asynchronous online activities such as online discussions may be conducted to engage students in interactive online learning. The online discussion should be accessed by students without technical issues. Teachers should check that students understand the use of threads. There should be strategies in place to encourage student participation in the discussion. The purpose of the online discussion and how it relates to the subject learning outcomes should be explained clearly. Teachers should inform students of what they are expected to do (Davis et al., 2019).

\subsection{Conducting online assessments}

The online assessments should be conducted with a clear purpose that may be formative or summative. There are various formats of assessments (e.g. take-home exams, essays, quizzes, discussions) for online learning and they should be appropriately designed and developed with online tools to assess students' attainment of the subject learning outcomes. Teachers should provide information about the purpose of the quiz (e.g., whether it is a practice test, a knowledge check) (Thomas and Graham, 2019).

Different assignment techniques and assessment types are used to examine various aspects of students' learning such as student participation (e.g. discussion forum, poll), student progress (e.g. quiz, short test), and student mastery level (e.g. short writing, mid-term test) (Al-Arimi, 2014). Teachers should create several versions of the test so that students do not all complete the same test and can attempt the quiz more than once. Teachers may also vary the order of the questions (and response stems for multiple-choice tests).

Teachers should inform students of marking criteria, submission method, assessment format, and due date. In addition, students should know what learning support and where to find it (Basantia, 2018). They are advised to make sure that the relevant technologies and tools are working properly before the online assessment. Students should be informed of how to get technical support when they experience technical difficulties during the assessment (Kotevski and Milenkoski, 2018).

Sufficient backup processes should be ready for students who encounter technical issues during the assessment. There should be mechanisms and approaches for avoiding plagiarism and maintaining academic integrity. Particularly, sufficient measures for preventing academic dishonesty such as randomizing the questions from a question bank and controlled environment with online tools must be adopted for online examinations and tests. These adopted measures should be made known to students in advance (Alston et al., 2017). Rubrics should be provided to students and are used to 
evaluate students' performance. Constructive, clear, and useful feedback of online assessments should be provided to students rapidly with the usage of online tools like announcements, emails, comments, and automatic feedback for an online test so that they can follow up on questions that they answered incorrectly.

\section{RESEARCH METHOD AND RESULTS}

To evaluate the effectiveness of the teaching strategies suggested in this paper, both the qualitative and quantitative research methods were used. Qualitative research was used to acquire an understanding of underlying opinions on teaching and learning activities. This provided insights into problems and uncovered students' thoughts and opinions. Interviews were used to gather unstructured and semi-structured data from students. Quantitative research was used to quantify problems and generate numerical data for statistical analysis. A survey was used to quantify opinions and attitudes and generalize outputs from students of a larger sample.

\subsection{Quantitative research results}

The online teaching strategies mentioned in the previous section were implemented in the business subjects taught by the author in the second semester of the academic year 2019-2020 at a university in Hong Kong. After the semester has been finished, a survey was conducted to collect feedback from 430 students who expressed their attitudes to various online teaching and learning practices discussed above. There are 32 questions in this survey as shown in Table 1. A typical 5-point Likert scale was used: (1) strongly disagree, (2) disagree, (3) neutral, (4) agree and (5) strongly agree.

Table 1: Questions of the survey collecting students' attitudes to online teaching practices and their average scores

\begin{tabular}{lcc}
\hline \multicolumn{1}{c}{ Survey Questions } & Average & Std. Dev. \\
\hline $\begin{array}{l}\text { No. Section 1: Conducting synchronize online interactive lessons } \\
\text { 1. Synchronous online lessons are conducted as far as possible. }\end{array}$ & 4.72 & 0.49 \\
2. All necessary learning materials, instruction and information about \\
the online platform are provided to you before the synchronous \\
$\begin{array}{l}\text { lesson. } \\
\text { The purpose of the session and how it relates to the learning } \\
\text { outcomes for the subject and what you are expected to do during the } \\
\text { session are clearly explained. }\end{array}$
\end{tabular}

\section{Section 2: Providing student support}

6. Regular online consultation opportunities are provided to you during the period of online teaching.

7. Your inquiries and requests are responded to within $24-48$ hours.

8. Regular communication with you is maintained via multiple means.

Section 3: Creating and using voice-over PowerPoint and videotaped lectures

9. The relevance of the lecture presented to the subject learning outcomes is clearly explained.

10. The video presentations are of appropriate length.

11. The audio quality of the presentations is good.

12. The lecture presentations can be accessed by you.

Section 4: Uploading PowerPoint slides and other teaching materials

13. Teaching materials (like readings, lecture notes, and online resources) in various formats are provided to you to enrich your learning experience.

14. Teaching materials are uploaded to the course site and can be 4.59 
accessed by you.

15. The teaching materials are presented logically and consistently. $\quad 4.51 \quad 0.69$

16. The teaching materials are of adequate audiovisual quality.

$4.37 \quad 0.68$

\section{Section 5: Conducting online asynchronous discussions}

17. The online discussion can be accessed by you without technical issues.

$4.51 \quad 0.51$

18. The purpose of the discussion and how it relates to the subject learning outcomes are clearly explained.

$4.26 \quad 0.48$

$4.55 \quad 0.50$

19. What you are expected to do and by when are clearly explained.

$4.69 \quad 0.49$ discussion.

Section 6: Conducting online assessments

21. Assessments in various formats for online learning are properly designed and developed with online tools to assess your attainment of the subject learning outcomes.

$4.49 \quad 0.54$

22. A variety of assignment types and assessment techniques are used to examine different aspects of students' learning, such as student mastery level, student progress, student participation that in turn inform further online learning and teaching.

23. Information about the assessment, including the due date, assessment format, submission method, and marking criteria is provided.

24. You are provided with information about what learning support is available and where to find it.

$4.54 \quad 0.60$

25. You are advised to check that the relevant tools and technologies are in working order before the online assessment.

$4.68 \quad 0.51$

$4.54 \quad 0.66$

$4.39 \quad 0.67$

$4.51 \quad 0.60$ students who experience technical difficulties during the assessment.

27. Adequate backup processes are in place for you when encountering technical issues during the assessment.

$4.47 \quad 0.53$

maintaining academic integrity.

29. Online tools are used to inform you of your assessment results and achievements of the respective learning outcomes that were assessed.

30. Mechanisms are in place to ensure fair marking and grading for online assessments.

$4.64 \quad 0.53$

$4.49 \quad 0.55$

$4.50 \quad 0.57$

students' work/performance.

$4.62 \quad 0.53$ provided to you promptly with the use of online tools.

As seen in Table 1 above, the average scores range from 4.26 to 4.72 indicating that, on a 5-point scale, students, in general, tend to agree that the quality of online teaching practices including synchronize online interactive lessons, student support, voice-over PowerPoint and videotaped lectures, uploading teaching materials, online asynchronous discussions, and online assessments.

\subsection{Qualitative research results}

Besides the survey, the author of the paper interviewed 40 students (selected from 430 students mentioned above) who studied in subjects taught by other teachers. Their qualitative feedback might reflect the general problems found in various subjects with different qualities of online teaching practices. The following issues were found and discussed in these interviews. 
- Teachers' familiarity with the usage of online teaching platforms

- Accessibility of online platforms, learning materials and their user-friendliness

- Technical issues (e.g., the stability of network connection, online platform compatibility with mobile devices)

- Responsiveness to students' needs/queries (e.g., instant feedback and explanation), effective communication and provision of sufficient support

- Quality of online learning materials (e.g., clarity in content delivery, well-prepared, easy to follow)

- Interaction between students and teachers

In particular, some students commented that online teaching cannot replace face-to-face teaching especially for subjects requiring skill-oriented, hands-on training, and the online environment provides a very different training and learning experience. Some felt more comfortable with raising questions in the online environment and got more interaction with teachers there. However, conducting group work is difficult in the online environment and they were concerned about meeting up in person to work on the group assignments. Some students also remarked that because of the slow and unstable network connection, they suffered from logging out of a live session occasionally. In addition, some online platforms did not perform well on mobile devices. Thus, it is recommended that uploading pre-recorded online sessions can help. This option is preferred by students because they can pause and playback lecturers whenever necessary. Absentees might download these materials and study whenever convenient.

\subsection{On-demand learning strategy suggested for the future}

The coronavirus epidemic creates disruptions to teachers and students who experience an exceptional situation in their schools. All are asked to do unexpected things regarding teaching and course delivery. Teachers may suffer from stress and fatigue because of the rushed professional development to facilitate online teaching and consider that students may not be able to attend courses immediately. Asynchronous activities may be more reasonable than synchronous ones. Flexible course syllabus and institutional policies should be adopted.

The threat of epidemic presented unique challenges for schools. Now students are used to learning independently and some may prefer learning remotely. They may be accustomed to less face-to-face collaboration, more freedom in their work, asynchronous assignments and shorter activities. Also, students may have experienced isolation and other challenges that need them to take time to process. Although the recent rapid and unplanned move to online teaching creates a poor users experience that is unfavorable to sustainable growth, a new education model with the integration of information technology will be accelerated and this will ultimately become an essential component of school education. This enables teachers to contact students more effectively through file sharing, voting, video meeting, and chat groups during this coronavirus epidemic that has entirely disrupted an education system. The move to online learning may result in the creation of a new and more efficient method of teaching students.

During the epidemic the importance of distributing knowledge across borders and all segments of society becomes clear. To be more practical for students facing unknown reality in the future, online learning will no longer contain classes at scheduled times and dates. Learning will be on-demand and it becomes the preferred learning method in society during a difficult period. Teachers may record their lectures and training sessions and make them online for students to access them when they want them. Teachers create self-paced versions of online lectures for those who cannot attend classes online. An on-demand course is completely self-paced compared with a regular online course. The on-demand course works best for students who are self-motivated and directed to finish learning activities at their own pace. It is not necessary to wait for the next available class and it becomes possible to learn anytime and anywhere. 
Classes are expected to be resumed completely or partially and the on-demand learning model may be applied when the epidemic starts to stabile. Students may meet for live teaching and learning activities either via live technologies like chats and webinars or in the classroom. For instance, students may be asked to attend a class every Monday and other days are non-compulsory. Teachers may answer questions online or meet students in a face-to-face manner on other days of the week. The attendance these days is optional and work may be finished online. The combination of face-toface and online instruction along with individualized learning strategies can enhance student learning. Online content is more dynamic and flexible than traditional textbooks. For example, to watch the instructional video for several times is beneficial for students. Blended learning can expand the limits of the classroom and allow students to continue to learn outside of school hours.

\section{CONCLUSION}

Because of the recent global spread of coronavirus, all the on-campus teaching activities have been suspended since February 2020. Teachers attempt to ensure that students can continue with their studies and conducting online teaching plays a key component. To ensure that students are with the best online learning experiences possible, this paper has suggested several ways of maintaining teaching quality in the online environment.

The effectiveness of online learning strategies is reliable on several factors. First, online learning platforms and technologies should be ready to provide courses to students remotely (Cohenmiller and Miller, 2019). Access to digital devices such as mobile phones and computers and Internet connectivity are major concerns in this aspect. Courses should be intentionally designed to enable accessibility and it is possible to customize and adjust the course content for individual needs. In addition, disadvantaged groups like those without connected digital devices and Internet connection should be supported (Meseguer-Martinez et al., 2017). For example, offline content like paper-based materials may be provided as an option of simple forms of communication. There are various digital learning management systems like Moodle and Google Classroom that helps students and teachers to connect and communicate remotely. Massive open online course platforms like Coursera and Edx provide online courses from leading educational institutions and well-recognized companies (UNESCO, 2020c).

Second, the teaching and learning materials are required to be revised for delivery through online platforms. Teachers should be engaged in the development of massive online learning programmes and the integration of pedagogical methodologies and technologies (Rhode et al., 2017). They should be able to support students to overcome disengagement and distance and adjust instructional designs to engage and motivate students.

Third, it is essential to monitor and evaluate the online learning process to find out the differences in students' participation and engagement (Nurse et al., 2018). Students with weak self-organization and self-regulation skills may need support and assistance from both teachers and parents. To provide supervision regularly can reduce the sense of disengagement and distance, and management disciplines and rules required for home-based learning.

Teachers and students face an extraordinary challenge in school closures to contain the spread of the coronavirus epidemic. Government and educational organizations deliver education remotely through various technologies to make sure learning objectives can be continuously attained. To establish online or distance learning strategies becomes a global response to unanticipated school closures. Learning and teaching activities should be reviewed and there may be alternative solutions with the support of teachers who plan and deliver learning programmers remotely (Miltenburg, 2018). 
Funding: This study received no specific financial support.

Competing Interests: The author declares that $\mathrm{s} /$ he has no conflict of interests.

Contributors/Acknowledgement: All the designing and estimation of current research done by the sole author.

Views and opinions expressed in this study are the views and opinions of the authors, Asian Journal of Empirical Research shall not be responsible or answerable for any loss, damage or liability, etc. caused in relation to/arising out of the use of the content.

\section{References}

Adnan, M., Kalelioglu, F., \& Gulbahar, Y. (2017). Assessment of a multinational online faculty development program on online teaching: Reflections of candidate e-tutors. Turkish Online Journal of Distance Education, 18(1), 22-38. doi.org/10.17718/tojde.285708.

Al-Arimi, A. (2014). Distance learning. Procedia - Social and Behavioral Sciences, 152(C), 82-88.

Alston, S., Moore, C., \& Thomas, M. (2017). Strategies for enhancing online teaching in social work education. Journal of Human Behavior in the Social Environment: Teaching, Research, and Practice: The HBCU (Historically Black Colleges and Universities) Perspective, 27(5), 412423. doi.org/10.1080/10911359.2017.1311817.

Antonova, D., Kunev, S., Hristov, T., \& Marinov, M. (2018). Concept of online distance learning system on sustainable development in the cross-border region. TEM Journal, 7(4), 915-923.

Basantia, T. (2018). Implementing practical based courses under open and distance learning system: a study of the perception of learners and counsellors. Turkish Online Journal of Distance Education, 19(2), 201-214. doi.org/10.17718/tojde.415838.

Cheng, B., Wang, M., Moormann, J., Olaniran, B., \& Chen, N. (2012). The effects of organizational learning environment factors on e-learning acceptance. Computers \& Education, 58(3), 885899. doi.org/10.1016/j.compedu.2011.10.014.

Cohenmiller, A., \& Miller, M. (2019). Resources for online teaching in the social and natural sciences: a multistage search and classification of open video repositories. College Teaching, 67(4), 243-249.

Davis, C., Greenaway, R., Moore, M., \& Cooper, L. (2019). Online teaching in social work education: understanding the challenges. Australian Social Work, 72(1), 34-46. doi.org/10.1080/0312407x.2018.1524918.

Educationdata. (2020). Online education statistics. Retrieved 28 June 2020. https://educationdata.org/online-education-statistics/.

Eichelberger, A., \& Leong, P. (2019). Using TPACK as a framework to study the influence of college faculty's beliefs on online teaching. Educational Media International, 56(2), 116133.

EY (2020). COVID-19 Assessing the impact on the education sector and looking ahead. Retrieved 28 June 2020. https://www.ey.com/Publication/vwLUAssets/ey-COVID-19-Assessing-theimpact-on-the-education-sector-and-looking-ahead/\$File/ey-COVID-19-Assessing-theimpact-on-the-education-sector-and-looking-ahead.pdf.

Guest, R., Rohde, N., Selvanathan, S., \& Soesmanto, T. (2018). Student satisfaction and online teaching. Assessment \& Evaluation in Higher Education, 43(7), 1084-1093.

Hess, N. (2011). Teaching Languages Online. TESOL Journal, 2(3), 373-375.

Hossain, A. (2020). Coronavirus may raise school dropout rate. Retrieved 28 June 2020. https://bangladeshpost.net/posts/coronavirus-may-raise-school-dropout-rate-36206.

Hsueh, P. R., Lee, P. I., Chiu, A. W. H., \& Yen, M. Y. (2010). Pandemic (H1N1) 2009 Vaccination and Class Suspensions after Outbreaks, Taipei City, Taiwan. Emerging Infectious Diseases, 16(8), 1309-311. https://www.ncbi.nlm.nih.gov/pmc/articles/PMC3298312/.

Jackson, C., Vynnycky, E., Hawker, J., Olowokure, B., \& Mangtani, P. (2013). School closures and influenza: systematic review of epidemiological studies. BMJ Open, 3(2), e002149. doi:10.1136/bmjopen-2012-002149.

Kotevski, Z., \& Milenkoski, A. (2018). Are free internet technologies and services the future of synchronous distance learning? Turkish Online Journal of Distance Education, 19(3), 4-14. doi.org/10.17718/tojde.444604. 
Lau, J. T. F., Griffiths, S., Au, D. W. H., \& Choi, K. C. (2011). Changes in knowledge, perceptions, preventive behaviours and psychological responses in the pre-community outbreak phase of the H1N1 Epidemic. Epidemiology and Infection, 139(1), 80-90. https://pubmed.ncbi.nlm.nih.gov/20800008/.

Malaga, R., \& Koppel, N. (2017). A comparison of video formats for online teaching. Contemporary Issues in Education Research, 10(1), 7-12.

Martin, F., Ritzhaupt, A., Kumar, S., \& Budhrani, K. (2019). Award-winning faculty online teaching practices: Course design, assessment and evaluation, and facilitation. The Internet and Higher Education, 42, 34-43.

Meseguer-Martinez, A., Ros-Galvez, A., \& Rosa-Garcia, A. (2017). Satisfaction with online teaching videos: A quantitative approach. Innovations in Education and Teaching International, 54(1), 62-67.

Miltenburg, J. (2018), Online teaching in a large, required, undergraduate management science course. INFORMS Transactions on Education, 19(2), 89-104.

Mohamad, S., Salleh, M., \& Salam, S. (2015). Factors Affecting Lecturers Motivation in Using Online Teaching Tools. Procedia - Social and Behavioral Sciences, 195, 1778-1784.

Nurse, R., Baker, K., \& Gambles, A. (2018). Library resources, student success and the distancelearning university. Information and Learning Science, 119(1/2), 77-86.

Reliefweb. (2020). Coronavirus school closures mean over one billion children and youth are now $\begin{array}{lllll}\text { shut out of classrooms. Retrieved } 28 & \text { June } 2020 .\end{array}$ https://reliefweb.int/report/world/coronavirus-school-closures-mean-over-one-billionchildren-and-youth-are-now-shut-out.

Phelan, J. (2015). The use of e-learning in social work education. Social Work, 60(3), 257-264.

Rhode, J., Richter, S., \& Miller, T. (2017). Designing personalized online teaching professional development through self-assessment. TechTrends, 61(5), 444-451.

Saadé, R., Morin, D., \& Thomas, J. (2012). Critical thinking in E-learning environments. Computers in Human Behavior, 28(5), 1608-1617.

Sharma, Y. (2020). Major international and national school exams suspended. University World $\begin{array}{llll}\text { News. } & \text { Retrieved } & 28 & \text { May }\end{array}$ https://www.universityworldnews.com/post.php?story=20200325174758462.

Thomas, J., \& Graham, C. (2019). Online teaching competencies in observational rubrics: What are institutions evaluating? Distance Education, 40(1), 114-132.

UNESCO (2020a). COVID-19 Educational Disruption and Response. Retrieved 28 March 2020. https://en.unesco.org/news/covid-19-educational-disruption-and-response.

UNESCO (2020b). Education: From disruption to recovery. Retrieved 18 May 2020. https://en.unesco.org/covid19/educationresponse.

UNESCO (2020c). More on UNESCO's COVID-19 Education Response. Retrieved 18 May 2020. https://en.unesco.org/covid19/educationresponse/solutions.

Voloshinov, S., Kruglyk, V., Osadchyi, V., Osadcha, K., \& Symonenko, S. (2020). Realities and prospects of distance learning at higher education institutions of Ukraine. Ukrainian Journal of Educational Studies and Information Technology, 8(1), 1-16.

Wang, V., \& Inouem, M. (2020). When can we go to school?' Nearly 300 million children are missing class. The New York Times. Retrieved 18 May 2020.

Witze, A. (2020). Universities will never be the same after the coronavirus crisis. Retrieved 28 June 2020. https://www.nature.com/articles/d41586-020-01518-y. 